\title{
Study design, originality and overall consistency influence acceptance or rejection of manuscripts submitted to the Journal
}

\author{
[Le devis de recherche, l'originalité et la cohérence générale des manuscrits soumis \\ au Journal influencent leur acceptation ou leur rejet]
}

Claudine Turcotte MD, Pierre Drolet MD FRCPC, Michel Girard MD MHPE FRCPC

Purpose: To identify the characteristics of the manuscripts submitted to the Canadian Journal of Anesthesia (CJA) associated with their acceptance or rejection and to analyze the reviewers' comments and their impact on the editors' decision to publish.

Methods: Peer review material was analyzed from 213 submissions to the CJA. Characteristics of accepted and rejected manuscripts were compared. Reviewers' comments were classified according to editorial criteria used by the journal and the distribution of the different types of comments amongst accepted and rejected submissions was compared.

Results: Characteristics of 213 manuscripts and comments from 405 reviewers were analyzed. Overall, 57\% of manuscripts submitted to the CJA were accepted. The type of research (study vs case report, clinical vs laboratory science) had no impact on the fate of the manuscripts; however, frequency of acceptance differed between articles originating from different geographic regions $(P<$ $0.000 \mathrm{I}$ ) with Canadian submissions posting the highest frequency (86\%). Comment analysis suggests that the relationship between the experimental design, the results, and the conclusion was the main determinant of an article's fate. Lack of originality or inappropriate experimental design were likely to be associated with rejection. Conversely, aspects involving the presentation of manuscripts (tables, figures, references) were rarely cited as reasons to justify acceptance or rejection.

Conclusion: Although articles are judged on many criteria, authors need to be aware that some aspects of a manuscript, namely the relationship between experimental design, results, and conclusions, the originality, and the use of an appropriate study design, are the most important features with regard to its acceptance or rejection.
Objectif : Déterminer les caractéristiques des manuscrits, soumis au Journal canadien d'anesthésie (JCA), qui sont associées à leur acceptation ou à leur rejet et analyser les commentaires des réviseurs ainsi que leur influence sur la décision de publier.

Méthode : Le matériel soumis à l'examen des pairs a été analysé à partir de 213 textes envoyés au JCA. Les caractéristiques des manuscrits acceptés et rejetés ont été comparées. Nous avons classé les commentaires des réviseurs selon les critères de la rédaction utilisés par le journal et nous avons comparé la distribution des différents types de commentaires concernant les textes acceptés et rejetés.

Résultats : Les caractéristiques de 213 manuscrits et les commentaires de 405 réviseurs ont été analysés. Globalement, $57 \%$ des manuscrits présentés au JCA ont été acceptés. Le type de recherche (étude vs observation de cas, science clinique vs science de laboratoire) n'avait pas d'impact sur le sort des manuscrits ; cependant, la fréquence d'acceptation était différente entre les articles provenant de différentes régions géographiques $(P<0,0001)$, les articles canadiens étant les plus souvent acceptés (86\%). L'analyse des commentaires montre que la relation entre le devis expérimental, les résultats et la conclusion constitue le principal déterminant de l'avenir d'un article. Le manque d'originalité ou un devis expérimental inapproprié risquent d'être associés à un rejet. Par ailleurs, les aspects concernant la présentation des manuscrits (tableaux, figures, références) sont rarement cités pour justifier l'acceptation ou le rejet.

Conclusion : Les articles sont jugés selon de nombreux critères, mais les auteurs doivent savoir que certains aspects d'un texte, soit la relation entre le devis expérimental, les résultats et la conclusion, l'originalité et l'utilisation d'une méthodologie appropriée sont les plus importantes caractéristiques de l'acceptation ou du refus d'un manuscrit.

From the Department of Anesthesia and Resuscitation, Maisonneuve-Rosemont Hospital, University of Montreal, Montreal, Quebec, Canada. Address correspondence to: Dr. Pierre Drolet, Département d'Anesthésie-Réanimation, Hôpital Maisonneuve-Rosemont, 5415 Boul. de

l'Assomption, Montréal, Québec HIT 2M4, Canada. E-mail: pdrolet@aei.ca Accepted for publication July 15, 2003.

Revision accepted March 24, 2004. 
$\mathrm{E}$ DITORS of medical journals receive numerous manuscripts that require peer review to decide their appropriateness for publication. Although peer review has been the focus of some analyses and observations, ${ }^{1-3}$ only a few research articles have been published on this matter. In 2001, Bordage reported the results of a study aimed at identifying reasons why reviewers recommend acceptance or rejection of a manuscript. ${ }^{4}$ The submissions studied by Bordage were research articles in the field of medical education. In his conclusions, the author highlighted problems common to many manuscripts and evaluated their influence on the decision to recommend or reject an article for publication. Amongst the problems plaguing manuscripts, flaws such as incorrect statistical analysis, overstating the results, or poor research design were all reasons commonly invoked by peer reviewers to recommend rejection. Still, we do not know if the characteristics of the review process and the reasons guiding the decision to accept or reject research articles in medical education are similar to the ones influencing publication in a clinical specialty such as anesthesiology.

The main goals of this study were to identify the characteristics of the manuscripts submitted to the Canadian Journal of Anesthesia (CJA) that were associated with their acceptance or rejection and to classify all of the peer reviewers' comments in order to analyze their impact on the decision to publish. This article should shed light on how reviewers use the different forms provided by the editor-in-chief to facilitate the peer review process and give authors and readers an in-depth look at some of the steps preceding publication.

\section{Methods}

The database used in this study included the forms and reviewers' comments pertaining to manuscripts submitted to the CJA from March 2000 to December 2000. Review articles, editorials, and correspondence were excluded. Otherwise, all submissions were analyzed. All material was obtained from the CJA editorial office with the permission of the Editor-in-chief. The peer review process of this paper was overseen by the associate editor, who was unaware of this study until its submission to the CJA.

The manuscripts included in this study were classified according to their geographical origin (Canada, United States, Europe, Asia, or other), their design (observational or experimental study vs case report), and their emphasis (clinical $v$ s laboratory). The association between these characteristics and the fate of the manuscript was evaluated.
It is the policy of the editorial board to send manuscripts submitted to the CJA to two peer reviewers for analysis. Whether they are members of the editorial board or guests, peer reviewers are chosen for their knowledge and expertise with regard to the subject of the article. Reviewers receive unblinded copies of the article and they advise the editor on acceptance or rejection. Reviewers are asked to proceed using three forms:

- a "manuscript review" checklist to be filled by reviewers and sent to the editor (Figure);

- a "reviewer's comments for authors" form that requests reviewers to consider 13 specific criteria while writing their comments (Table I); and

- a space reserved for comments to be read by the editor only.

The comments for authors and editor were read carefully and classified as positive or negative remarks. Specific comments regarding grammar, spelling and syntax were disregarded. All other comments to authors were further analyzed and divided according to their relevance to one of the 13 criteria suggested by the editorial board and listed in Table I. When particular comments for authors could not be assigned to one of the 13 criteria, they were noted as unclassified. Unclassified comments were also analyzed and assigned, if possible, to new categories. Because of their small number, comments for the editor were not divided according to the 13 criteria suggested in the review process. The classification of the comments was accomplished primarily by the first author (C.T.). Although the assignment was, by nature, a subjective process, less than 20 comments proved difficult to assign. Those few comments were classified following discussion and agreement between the investigators.

The characteristics of the peer review material were compared according to the fate of the manuscripts (acceptance or rejection). Data from the checklist and characteristics such as geographical origin and type of submissions (studies vs case reports; clinical vs laboratory) were analyzed with the Chi-square test. The number of comments for editor and for authors, the latter being divided according to the 13 criteria suggested in the review process, was analyzed with Fisher's exact test or the Chi-square test for trends with Bonferroni's correction for multiple comparisons. The Spearman correlation coefficient was used to measure the strength of the association between formal recommendations submitted by both reviewers regarding acceptance or rejection. To do so, each of the four possible recommendations ("accept as is," "accept following appropriate revision," "possibly accept following revision," and "reject") was treated as an item on an ordinal scale. A $P$ value $<0.05$ was considered significant. 


\section{MANUSCRIPT REVIEW \\ Comments for Editorial Boand Onty}

Revicwer:

Title of paper:

Ref \# :

Author(s):

$\begin{array}{llll}\text { Originality } & \square \text { Yes } & \square \text { No } & \square \text { Not applicable } \\ \text { Scientific } & \square \text { Acceptable } & \square \text { Unacceptable } & \square \text { Not applicable } \\ \text { Data Analysis } & \square \text { Appropriate } & \square \text { Inappropriate } & \square \text { Uncertain } \square \text { Not upplicable } \\ \text { Significance/Importance } & \square \text { Yes } & \square \text { No } & \\ \text { Preacntation } & \square \text { Acceptable } & \square \text { Unacceptable } & \end{array}$

Recommendations $\square$ Accept as is

$\square$ Accept following appropriate revision

Editorial Desirable $\Pi$ Yes (If yes, suggest author below)

\author{
$\square$ Pasibly accept following revision \\ $\square$ Reject
}

FIGURE Manuscript review checklist provided to peer reviewers in 2000 for the Canadian Journal of Anesthesia.

\section{Results}

Two hundred and thirteen manuscripts were analyzed. Amongst them, 121 were accepted and 92 were rejected for publication (proportion accepted, 57\%). Thirty manuscripts (2l accepted, nine rejected) were scrutinized by only one peer reviewer; thus, a total of 405 peer reviews were studied. Significant differences between accepted and rejected manuscripts were noted for all items found on the manuscript review checklist (Table II). A significant difference was also noted in the distribution of accepted and rejected manuscripts by geographical origin of the submissions (Table III). The difference stemmed from a high proportion of accepted manuscripts from Canada (86\%) and a lower proportion from Asia (41\%). The frequency of acceptance of case reports $(32 / 60 ; 53 \%)$ did not differ significantly from that of studies $(89 / 153 ; 58 \% ; P=0.45)$. Similarly, the frequency of acceptance of laboratory reports $(12 / 30 ; 40 \%)$ was not significantly different from that of clinical matters $(109 / 183 ; 59 \% ; P=0.12)$.
A total of 3,722 comments for authors were written by peer reviewers. Table IV shows the mean number of comments for authors divided into the 13 criteria suggested for the review of manuscripts. Reviews for accepted and rejected manuscripts contained an average of 1.4 and 0.9 comments respectively that were not classifiable into the 13 criteria. Most of these comments were of a general nature (e.g., "enjoyed reading," "worth nothing"). The only new criterion that could be extrapolated from these unclassified comments pertained to the clinical relevancy of the submitted manuscripts. As a criterion, clinical relevancy was the object of 0.1 comments amongst reviews for accepted and rejected manuscripts. Table V identifies criteria for which there were differences between accepted and rejected submissions with regard to the number of comments for authors.

Regarding positive comments for the editor, reviewers wrote a mean of 0.9 comments compared to 0.6 comments for accepted and rejected manuscripts, respectively $(P=0.006)$. In the same way, negative 
TABLE I Criteria suggested by the editorial board for the review of manuscripts submitted to the Canadian Journal of Anesthesia

\begin{tabular}{ll}
\hline 1 & Information original, in total or in part? \\
2 & Any concerns about ethics? \\
3 & Title appropriate, informative? \\
4 & Experimental design appropriate? \\
5 & Methods used are adequately described and appropriate? \\
6 & Methods of data analysis appropriate? \\
7 & Results clearly described? Tables, figures appropriate? \\
8 & Conclusions appropriate in relation to experimental design \\
& and results? \\
9 & Discussion appropriate and complete? \\
10 & Abstract precise and complete? \\
11 & Should any portion be expanded, condensed, eliminated? \\
12 & All relevant references cited? Excessive number cited? \\
13 & CJA appropriate for this manuscript? \\
\hline
\end{tabular}

CJA = Canadian Journal of Anesthesia.

TABLE II Peer reviewers' responses to items on the manuscript review checklist for 213 manuscripts

\begin{tabular}{|c|c|c|}
\hline & $\begin{array}{l}\text { Accepted } \\
(n=121)\end{array}$ & $\begin{array}{l}\text { Rejected } \\
(n=92)\end{array}$ \\
\hline \multicolumn{3}{|l|}{ Originality $(P<0.0001) *$} \\
\hline Yes/Yes & 57 & 27 \\
\hline Yes/No & 21 & 21 \\
\hline Yes/Not applicable & 11 & 3 \\
\hline Yes/Other† & 25 & 8 \\
\hline $\mathrm{No} / \mathrm{No}$ & 5 & 22 \\
\hline No/Not applicable & 0 & 2 \\
\hline No/Other $\dagger$ & 2 & 7 \\
\hline Not applicable/Not applicable & 0 & 0 \\
\hline Not applicable/Other† & 0 & 0 \\
\hline Other†/Other $†$ & 0 & 2 \\
\hline \multicolumn{3}{|l|}{ Scientific $(P<0.0001) *$} \\
\hline Acceptable/Acceptable & 42 & 15 \\
\hline Acceptable/Unacceptable & 25 & 23 \\
\hline Acceptable/Not applicable & 15 & 5 \\
\hline Acceptable/Other† & 21 & 7 \\
\hline Unacecceptable/Unacecceptable & 2 & 18 \\
\hline Unacceptable/Not applicable & 1 & 11 \\
\hline Unacceptable/Other $†$ & 4 & 3 \\
\hline Not applicable/Not applicable & 7 & 6 \\
\hline Not applicable/Other† & 4 & 3 \\
\hline Other†/Other† & 0 & 1 \\
\hline \multicolumn{3}{|l|}{ Data analysis $(P<0.0001)$ * } \\
\hline Appropriate/Appropriate & 30 & 12 \\
\hline Appropriate/Inappropriate & 13 & 19 \\
\hline Appropriate/Uncertain & 11 & 6 \\
\hline Appropriate/Not applicable & 5 & 1 \\
\hline Appropriate/Other & 14 & 4 \\
\hline Inappropriate/Inappropriate & 1 & 8 \\
\hline Inappropriate/Uncertain & 3 & 7 \\
\hline Inappropriate/Not applicable & 1 & 6 \\
\hline Inappropriate/Other† & 3 & 4 \\
\hline Uncertain/Uncertain & 3 & 2 \\
\hline Uncertain/Not applicable & 3 & 0 \\
\hline
\end{tabular}

TABLE II continued

\begin{tabular}{|c|c|c|}
\hline & $\begin{array}{l}\text { Accepted } \\
(n=121)\end{array}$ & $\begin{array}{l}\text { Rejected } \\
(n=92)\end{array}$ \\
\hline Uncertain/Other $\dagger$ & 6 & 1 \\
\hline Not applicable/Not applicable & 19 & 17 \\
\hline Not applicable/Other $†$ & 7 & 4 \\
\hline Other†/Other† & 2 & 1 \\
\hline \multicolumn{3}{|l|}{ Significance/Importance $(P<0.0001)$ * } \\
\hline Yes/Yes & 46 & 10 \\
\hline Yes/No & 31 & 30 \\
\hline Yes/Other† & 31 & 12 \\
\hline No/No & 7 & 25 \\
\hline No/Other $†$ & 6 & 14 \\
\hline Other $\dagger$ /Other $\dagger$ & 0 & 1 \\
\hline \multicolumn{3}{|l|}{ Presentation $(P=0.01)$ * } \\
\hline Acceptable/Acceptable & 36 & 17 \\
\hline Acceptable/Unacceptable & 36 & 33 \\
\hline Acceptable/Other $†$ & 21 & 11 \\
\hline Unacceptable/Unacceptable & 12 & 20 \\
\hline Unacceptable/Other $†$ & 13 & 10 \\
\hline Othert/Other $†$ & 3 & 1 \\
\hline \multicolumn{3}{|l|}{ Recommendation $(P<0.0001)$ * } \\
\hline Accept as is/Accept as is & 0 & 0 \\
\hline Accept as is/Accept following revision & 9 & 1 \\
\hline Accept as is/Possibly accept & 4 & 1 \\
\hline Accept as is/Reject & 1 & 3 \\
\hline Accept as is/Other $†$ & 1 & 0 \\
\hline $\begin{array}{l}\text { Accept following revision/Accept } \\
\text { following revision }\end{array}$ & 25 & 0 \\
\hline Accept following revision/Possibly accept & 35 & 4 \\
\hline Accept following revision/Reject & 12 & 20 \\
\hline Accept following revision/Other† & 13 & 4 \\
\hline Possibly accept/Possibly accept & 6 & 5 \\
\hline Possibly accept/Reject & 6 & 20 \\
\hline Possibly accept/Other† & 6 & 2 \\
\hline Reject/Reject & 1 & 20 \\
\hline Reject/Other† & 1 & 11 \\
\hline Other†/Other $†$ & 1 & 1 \\
\hline
\end{tabular}

For each item, the combinations of responses given by the two peer reviewers are listed. *For each item, the $P$-value is for the comparison between accepted and rejected manuscripts using the Chi square test with $P<0.05$ being statistically significant. †"Other" refers to no responses or responses other than check marks.

comments (mean 1.9) were written more frequently for rejected manuscripts compared to accepted articles (mean $1.2 ; P=0.0004$ ).

The correlation between the formal recommendations to accept or reject a manuscript provided by the two reviewers (last item of the checklist) was low $(\mathrm{r}=$ $0.17 ; 95 \%$ confidence interval -0.02 to 0.29 ). 


\section{Discussion}

Experts in the field of medical publishing have published recently a lengthy report on the review criteria to be used for research manuscripts. ${ }^{5}$ Still, the peer review process is viewed by many as something that is less than systematic. Even if standard forms and tools are available to reviewers of many journals, ${ }^{6,7}$ editors frequently need to decide the fate of a manuscript based on ambiguous, and sometimes contradictory, opinions. Analysis of the manuscript review checklist provided to reviewers of the CJA revealed significant differences between accepted and rejected submissions with regard to all items (Table II) and suggests that the checklist is discriminative and useful. Thus, it is important for authors to write manuscripts that can comply with the criteria of the checklist. However, the poor correlation between reviewers regarding the recommendation to publish or reject highlights the difficulty for an editor to rely on a single instrument. Others have noted the lack of agreement between peer reviewers. ${ }^{8}$ Hence, other tools are necessary. To be useful, these tools must allow the reviewers to form

TABLE III Accepted and rejected manuscripts by geographical origin

\begin{tabular}{lll}
\hline & Accepted $^{*}(n=121)$ & Rejected $^{*}(n=92)$ \\
\hline Canada & 36 & 6 \\
United States & 22 & 14 \\
Europe & 22 & 14 \\
Asia & 40 & 57 \\
Others & 1 & 1 \\
\hline
\end{tabular}

${ }^{*} P<0.0001$ for the distribution of accepted and rejected manuscripts by geographical origin. and communicate opinions toward the manuscript that are both clear and systematically presented. Even divergent opinions, if they are clearly stated and argued, will help the editor decide what to do with a manuscript. ${ }^{9}$ A few months after data were collected for this study, the CJA started using an expanded checklist with more items. In addition to the items studied in this article, reviewers are now asked to comment on the hypothesis and objectives stated in the submitted manuscript and to suggest if a statistical or an ethics review is required.

The "comments for authors" section was the most elaborate part of the peer review documents. Each peer review analyzed for this study contained a mean of nine comments for authors. Peer reviewers were asked to comment on the 13 criteria proposed by the editorial board (Table I). The 3,722 comments for authors found in the 405 peer reviews were classified according to these criteria by the investigators of this study (mostly by C.T.). Since comments were written in prose, the classification was subjective by nature, entailed decisions based on judgment, and is one of the limitations of this study since we cannot exclude that other researchers might have opted to assign some comments to a different category. Whenever a comment could belong to more than one category, it was assigned to the category best dictated by the context in which it appeared. Only two criteria, "methods used are adequately described and appropriate?" and "discussion appropriate and complete?," were the object of more than one comment, on average, in all reviews, whether the manuscripts were accepted or not. Three criterias, "conclusions appropriate in relation to experimental design?," "results clearly

TABLE IV Number of comments for authors per peer review divided according to review criteria and fate of manuscript

\begin{tabular}{llc}
\hline Review criterion & Accepted $(n=121)$ & Rejected $(n=92)$ \\
& & mean (range) \\
\hline Information original, in total or in part? & $0.2(0-2)$ & $0.27(0-2)$ \\
Any concerns about ethics? & $0.09(0-2)$ & $0.05(0-1)$ \\
Title appropriate, informative? & $0.17(0-3)$ & $0.12(0-2)$ \\
Experimental design appropriate? & $0.63(0-6)$ & $0.84(0-6)$ \\
Methods used are adequately described and appropriate? & $1.13(0-9)$ & $1.44(0-10)$ \\
Methods of data analysis appropriate? & $0.28(0-5)$ & $0.53(0-7)$ \\
Results clearly described? Tables, figures appropriate? & $1.06(0-8)$ & $0.93(0-18)$ \\
Conclusions appropriate in relation to experimental design and results? & $1.04(0-6)$ & $0.53(0-7)$ \\
Discussion appropriate and complete? & $1.66(0-7)$ & $1.49(0-11)$ \\
Abstract precise and complete? & $0.27(0-4)$ & $0.15(0-3)$ \\
Should any portion be expanded, condensed, eliminated? & $0.98(0-11)$ & $0.97(0-8)$ \\
All relevant references cited? Excessive number cited? & $0.31(0-3)$ & $0.2(0-3)$ \\
Canadian Journal of Anesthesia appropriate for this manuscript? & $0.09(0-2)$ & $0.07(0-2)$ \\
Unclassified comments & $1.41(0-8)$ & $0.84(0-5)$ \\
Total & $9.32(0-24)$ & $8.43(0-48)$ \\
\hline
\end{tabular}


TABLE V Number of comments for authors per review divided according to review criteria, fate of manuscript, and type of comment

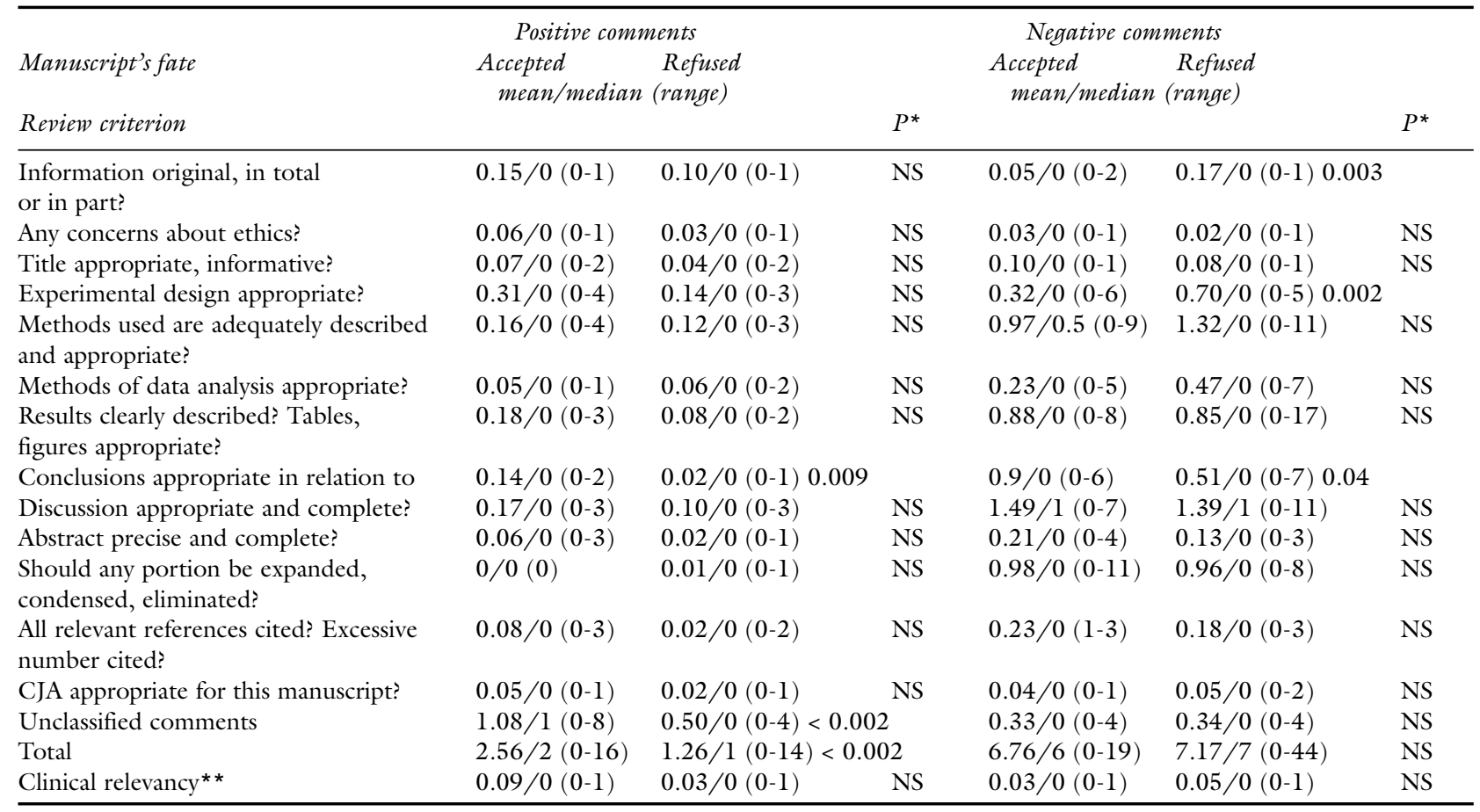

*Comparisons between published and rejected articles regarding the number of comments. Since 13 criteria were analyzed, the $P$-value reported is corrected according to Bonferroni's method for 13 comparisons. ${ }^{*}$ Comments regarding clinical relevancy are extracted from unclassified comments. CJA = Canadian Journal of Anesthesia.

described? Tables, figures appropriate?" and the unclassified comments, received more than one comment from peer reviewers, but only for accepted manuscripts. In contrast, two criteria ("any concern about ethics?," "CJA appropriate for this manuscript?") were the subject of less than 0.1 comments, on average.

If Table IV shows the criteria that were addressed most often by peer reviewers, Table $\mathrm{V}$ identifies the most discriminating ones with regard to acceptance or rejection. "Conclusions appropriate in relation to experimental design and results?" was the only criterion showing differences regarding the number of comments, both positive and negative, between accepted and rejected manuscripts. Surprisingly, more negative comments were seen amongst accepted articles than amongst rejected ones. Other criteria showed differences in the number of comments between accepted and rejected manuscripts, but only with regard to either positive (unclassified comments) or negative comments ("information original, in total or in part?" and "experimental design appropriate?"). Analysis of these results suggests that the relationship between the study design, the results, and the conclusions may be of greatest interest to peer reviewers when they are commenting on a manuscript and deciding its fate. On the other hand, some aspects of a manuscript's presentation (tables and figures) were unlikely to play a major role in the decision to accept or reject a submission, although they were the object of many comments. Table $\mathrm{V}$ also shows that a majority of peer reviewers chose to not address systematically all the specific criteria proposed by the editorial board. Whether the review process could benefit from eliminating or modifying some of the less discriminating or less addressed criteria is beyond the scope of this study.

References have been found to be notoriously inaccurate in many published articles. ${ }^{10,11}$ This issue has been addressed by some journals, including the CJA, which requests authors to send the title page of all references with the final version of accepted manuscripts. Neither were references a popular topic amongst reviewers nor did they impact significantly on the fate of a manuscript.

Clinical relevancy, the only criterion that could be extrapolated from the unclassified comments, was also unlikely to be singled out as a cause for acceptance or 
rejection although other investigators of medical publication have emphasized the importance for a study to be clinically relevant. ${ }^{12}$ Conversely, the originality of the material submitted and the quality of the experimental design, even if they were not particularly praised in accepted manuscripts, were identified as reasons for recommending rejection by reviewers when deemed faulty.

It was customary for reviewers to comment negatively on the relationship between conclusions, study design, and results. Surprisingly, these negative comments seemed to reflect favourably on the decision to publish. This suggests that, although many authors had the tendency to overinterpret their results, this did not seem to be a major flaw. ${ }^{4}$ Instead, our analysis suggests that when reviewers took time to comment on what could be construed as an excess of enthusiasm in interpreting results, the article probably deserved to be published after due revision. Others have suggested that even negative comments can contribute to the improvement of a submission, if they are formulated in a constructive manner. ${ }^{13}$

The "comments for editor" section was used sparingly by peer reviewers. On average, it contained only two comments (positive or negative). Still, it was quite discriminating since both types of comments, positive and negative, showed differences between accepted and rejected submissions. The importance of reviewers' comments can hardly be overemphasized since a study conducted amongst North American editors showed that about half of them relied exclusively on these comments to decide the fate of manuscripts. ${ }^{14}$

This study shows that, in spite of some criticisms and reservations appearing in recent literature regarding the place of case reports, ${ }^{15,16}$ they are accepted as frequently as other studies in the CJA. The clinical nature of the CJA and of anesthesiology may facilitate the acceptance of case reports. ${ }^{17}$ Link suggested that reviewers may evaluate papers submitted by authors coming from their own country more favourably. ${ }^{18}$ Our data do not allow us to comment or speculate on the impact of this phenomenom on the high proportion for Canadian submissions accepted for publication.

In conclusion, manuscripts submitted to a clinical journal like the CJA are subjected to a complex process of peer review. The forms provided to reviewers need to be discriminating while promoting a systematic approach. Analysis of the responses provided by peer reviewers to the CJA showed that many factors are influential in the decision to publish a manuscript. These factors have to be taken into account by authors who wish to publish an article. The relationship between the study design, the results, and the conclusions may be the most important element amongst the peer review criteria and should generate enough interest so that the reviewers will take time to comment constructively on this topic. Some presentation elements (tables, figures, references) are unlikely to be cited as causes for acceptance or rejection. On the other hand, lack of originality or inappropriate study design will influence reviewers to recommend rejection of a manuscript.

\section{Acknowledgement}

We wish to thank the Editor-in-chief of the Canadian Journal of Anesthesia, Dr. Jean-François Hardy, for giving us access to the material needed to build the database used in this study.

\section{References}

1 Feurer ID, Becker GJ, Picus D, Ramirez E, Darcy MD, Hicks ME. Evaluating peer reviews. Pilot testing of a grading instrument. JAMA 1994; 272: 98-100.

2 Evans $A T, M c N u t t R A$, Fletcher SW, Fletcher RH. The characteristics of peer reviewers who produce goodquality reviews. J Gen Intern Med 1993; 8: 422-8.

3 Black N, van Rooyen S, Godlee F, Smith R, Evans S. What makes a good reviewer and a good review for a general medical journal? JAMA 1998; 280: 231-3.

4 Bordage G. Reasons reviewers reject and accept manuscripts: the strengths and weaknesses in medical education reports. Acad Med 2001; 76: 889-96.

5 Joint Task Force of Academic Medicine and the GEARIME Committee. Review criteria for research manuscripts. Acad Med 2001; 76: 897-978.

6 Bligh J. What happens to manuscripts submitted to the Journal? (Editorial) Med Educ 1998; 32: 567-70.

7 Nylenna M, Riis P, Karlsson Y. Multiple blinded reviews of the same two manuscripts. Effects of referee characteristics and publication language. JAMA 1994; 272: 149-51.

8 Cullen DJ, Macaulay A. Consistency between peer reviewers for a clinical specialty journal. Acad Med 1992; 67: 856-9.

9 Eckberg $D L$. When nonreliability of reviews indicates solid science. Behav Brain Sci 1991; 14: 145-6.

10 Eichorn P, Yankaner A. Do authors check their references? A survey of accuracy of references in three public health journals. Am J Public Health 1987; 77: 1011-2.

11 Evans JT, Nadjari HI, Burchell SA. Quotational and reference accuracy in surgical journals. A continuing peer review problem. JAMA 1990; 263: 1353-4.

12 Rosenfeld RM. The seven habits of highly effective data users (Editorial). Otolaryngol Head Neck Surg 1998; 118: 144-58. 
13 Purcell GP, Donovan SL, Davidoff F. Changes to manuscripts during the editorial process. Characterizing the evolution of a clinical paper. JAMA 1998; 280: 227-8.

14 Wilkes MS, Kravitz RL. Policies, practices, and attitudes of North American medical journal editors. J Gen Intern Med 1995; 10: 443-50.

15 Fox $R$. Writing a case report: an editor's eye view. Hosp Med 2000; 61: 863-4.

16 Wright SM, Kouroukis C. Capturing zebras: what to do with a reportable case. CMAJ 2000; 163: 429-31.

17 Vandenbroucke JP. In defense of case reports and case series. Ann Intern Med 2001; 134: 330-4.

18 Link AM. US and non-US submissions. An analysis of reviewer bias. JAMA 1998; 280: 246-7. 